\title{
Daskyleion Kare Planlı Yapı Üzerine Yeni Gözlemler
}

\section{New Investigations on "The Square-Plan Building" at Dascyleum}

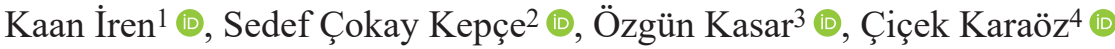

1Sorumlu yazar/Corresponding author: Kaan İren (Prof. Dr.),

Muğla Sıtkı Koçman Üniversitesi, Arkeoloji ve Arkeometri Uygulama ve Araştırma Merkezi,

Muğla, Türkiye

E-mail: kaaniren@posta@mu.edu.tr

Orcid ID: 0000-0002-9053-8693

2Sedef Çokay Kepçe (Prof. Dr.),

İstanbul Üniversitesi, Edebiyat Fakültesi, Arkeoloji Bölümü, Klasik Arkeoloji Ana Bilim Dalı,

İstanbul Türkiye

E-mail: cokays@istanbul.edu.tr

Orcid ID: 0000-0002-2574-8723

3Özgün Kasar (Öğr. Gör.),

Muğla Sıtkı Koçman Üniversitesi, Arkeoloji ve

Arkeometri Uygulama ve Araştırma Merkezi,

Muğla, Türkiye

E-mail: ozgunkasar@mu.edu.tr

Orcid ID: 0000-0002-7806-5221

${ }^{4}$ Çiçek Karaöz (Araş. Gör.),

Muğla Sıtkı Koçman Üniversitesi,

Edebiyat Fakültesi, Arkeoloji Bölümü,

Muğla, Türkiye

E-mail: cicekatay@hotmail.com

Orcid ID: 0000-0002-7682-0326

Başvuru/Submitted: 24.12 .2019

Kabul/Accepted: 25.12.2019

Atıf/Citation: Iren, K., Cokay Kepce, S., Kasar, O., Karaoz, C. (2020). Daskyleion kare planlı yap üzerine yeni gözlemler. Anadolu AraştırmalarıAnatolian Research, 22, 129-146.

https://doi.org/10.26650/anar.2019.22.664304

\section{öz}

Günümüzde Balıkesir İli, Bandırma İlçesi, Ergili Mahallesi'nde yer alan ve Hisartepe olarakadlandırılan alanın doğusundakiyamaçta, 2011 yılında kule olaraknitelendirilen bir yapı ortaya çıkarılmıştır. Bu alanda yürütülen kazı çalışmalarıyla, kare plana sahip bu yapının doğu yönünde açığa çıkarılan duvarların toplam dört evreyi kapsadığı anlaşılmıştır. İlk yapı evresi kare planlı yapının kuzeydoğu köşesinde açılan sondajın en dibinde ortaya çıkan ve destek duvarının dış yüzünü oluşturan duvarın aksından daha farklı bir aksa sahip bir duvar ile doğuya doğru, ona dik açı yaparak organik olarak birleşen bir duvardan oluşan evredir. Bu yapı evresinin üzerine ikinci yapı evresi olarak eğimli/basamaklı yapıya sahip destek duvarı (glacis), ilk yapı evresindeki duvarların üzerine oturacak şekilde ama farklı bir aksta inşa edilmiştir. Üçüncü yapı evresinde destek duvarının önünde/doğusundaki alan toprakla doldurulmuş ve üzerine kare planlı yapı inşa edilmiştir. Dördüncü bir yapı evresindeyse kare planlı yapının doğusunda, yapının doğu duvarına paralel bir şekilde uzanan, dış yüzü aşağı yukarı benzer büyüklük ve şekillerde taşların dizilmesiyle oluşturmuş ve iki duvar arasındaki boşluğa doldurulmuş dolgu taşlarını sınırlayan, kaldırım benzeri bir mimari unsur inşa edilmiştir. Bu çalışma, söz konusu alanda açığa çıkarılan yapı kalıntılarının, kazıda ele geçen buluntulara ve Gordion, Antandros gibi yerleşmelerindeki benzerlerine dayanılarak tarihlendirilmesini içermektedir. Ayrıca, çalışmada kare planlı yapının işlevi ile ilgili ilk tespitlerimiz yer almaktadır.

Anahtar Kelimeler: Daskyleion, Kare Planlı Yapı, Glacis, Podyumlu Mezar

\section{ABSTRACT}

During excavations in Dascyleum in 2011, a structure was discovered and was identified as a tower located on the slope east of an area called Hisartepe in Ergili, located in the Bandırma District of Balıkesir Province. The excavations revealed that this square-plan structure was constructed over four building phases. During the first phase, a wall at the bottom northeastern corner of the structure was constructed. The second phase added a support wall (glacis) with a stepped structure that is built on the first building phase, but on a different axis to fit on top of the walls built during the first phase. In the third phase, the area in the eastern part of the glacis was filled with soil and a square structure was built on top of it. In the fourth phase, a pavement-like architectural element was constructed to the east of the building, parallel to the eastern wall of the building. The present study includes the dating of the buildings' remains and presents the initial conclusions as to the function of the square-plan structure.

Keywords: Dascyleum, Square Planned Building, Glacis, Podium Tomb 


\section{EXTENDED ABSTRACT}

Dascyleum is an archaeological site in Hisartepe and the surrounding area, located on the coast of Manyas Lake. The site is also located close to the present-day village of Ergili and lies $30 \mathrm{~km}$ to the south of the present-day city of Bandirma in northwestern Anatolia. Daskyleion was an Anatolian city during the Iron Age. Although Phrygian and Lydian cultures were clearly present in Daskyleion at one time, the city's zenith occurred during the Persian period when the city served as the satrapal center. During this time, the eastern slope of Hisartepe was used as the entrance to the Acrodascyleum because of the main gate of a medieval castle. This is a stepped road, most probably from the $4^{\text {th }}$ century BC, and it was dated to the Early Middle Ages. Many circuit walls throughout the ages defended this side of the hill.

A square-plan structure was discovered in 2011 as part of geophysical prospections on the same side. An investigation was subsequently launched. The location of the building makes it suitable to have been used as an entrance to the settlement. Remains of a tower approximately 10 meters north of this building had already been discovered. Therefore, the building was assumed to be another tower belonging to the gate building. To determine the structure's function, test-pits were excavated on the eastern side of the building, and it was discovered that the building was constructed on a sloping wall (i.e., a glacis).

Four construction phases for the square-plan structure were observed, including the sloping wall (glacis) that the structure rested upon. Under the glacis, four wall rows were unearthed, which were oriented in a different direction from the glacis. We consider this to be potentially the first phase of building. Moreover, the masonry technique of the wall appears clumsy. The first phase was brought to an end by a flood, carrying white clay, small stones, and sand. There is a very small amount of archaeological material on this level, proving our thesis. The glacis is constructed on this wall, but in a different direction. This could be considered the next phase. Using pottery shreds, the construction of the first and second phases were dated to circa $700-550$ or 525 BC. In the third phase, the area in front of the glacis was filled with dirt and the square-plan structure was built on top of it. The most recent datable material from this area belongs to the $4^{\text {th }}$ century BC. In the fourth phase, a paved area was added to the eastern part of the building. It is difficult to determine when the paved area was added, but this likely occurred after the construction of the building.

The square-plan structure is constructed of andesite. Some stones of the square-plan structure were skived and some display anathyrosis of different widths. However, they are the same height, which implies that finalization had not yet been achieved. The interior of the building was filled with small stones; it could be argued that the building was a grave podium, but not a military tower. Xanthus, Nereid Monument, Mausoleum of Halicarnassus, and Belevi Monument all have a similar structure. 
To summarize, there were four construction phases observable in the excavation of the square-plan structure. The glacis was erected on a hill during the Lydian Period, similar to other Anatolian cities. A similar wall surrounds the Gordion Citadel. After the destruction of Gordion in the $8^{\text {th }}$ century $\mathrm{BC}$, a retaining wall (glacis) was constructed. The core of this wall includes rubble stones and has a stepped wall with regular trimmed stones. The Dascyleum example also has a stepped wall and a sloping façade. The square-plan structure was erected in the $4^{\text {th }}$ century BC. Although it is difficult to determine its function, it is clear that the building must have been among the most important architectural elements in the city during the $4^{\text {th }}$ century BC. The stepped road, which passes by the north of the square-plan structure, was built later. 


\section{Giriş}

Balıkesir İli Bandırma İlçesi Ergili Mahallesi'nde yer alan Daskyleion İlk Çağ kentinin üzerine kurulduğu Hisartepe'nin doğu yamac1, yerleşimin kuruluşundan beri giriş olarak kullanılmıştır. Bu alanda yer alan ve daha önceki yıllarda ortaya çıkarılmış olan Orta Çağ Kuleleri, MÖ 4. yüzyıl yolu, bunun hemen altında yer alan yine MÖ 4. yüzyılın daha erken bir evresine ait basamaklı giriş yapısı, MÖ 5. ve 4. yy teras sur duvarları, yolun iki yanında yer alan kare planlı büyük yapılar kentin girişi ve tahkimatıyla ilgili yapılardır. Bunların arasından çalışmanın konusunu oluşturan "Kare planlı yapı” ilk olarak 2011 kazı sezonunda jeofizik çalışmalarının sonucu olarak araştırılmaya ve ortaya çıkarılmaya başlamıştır. Yukarıda da değinildiği gibi yapının mevcut konumu, yerleşmeye girişin sağlandığ 1 yamacın nispeten düzlüğe kavuştuğu güney kısmındadır ve yaklaşık $10 \mathrm{~m}$ kadar güneyinde kule benzeri bir yapı bulunmaktadır. Dolayısıyla çalışmalar sırasında bu makalenin konusunu oluşturan yapının elverişli konumu ve diğer yapıyla olan benzerliği nedeniyle bir kule yapısı olabileceği düşünülmüştü. Bununla beraber yapılan kazı çalışmalarıyla daha farklı bir mimari unsuru içeriyor olabileceği ileri sürülebilir.

\section{Araştırma Bulguları}

2011 yılında bir kısmı ortaya çıkarılan söz konusu kare planlı yapının, batı sınırı henüz belli olmamakla birlikte doğudaki uzun kenarı 10,45 m ölçülerinde, kuzeydeki kısa kenarda ise 5,33 m ölçülerindedir (Resim 1). Yüksekliği kuzeyde 1,37 m, güneyde ise 3,17 m’yi bulmaktadır. Yapıda ağırlıklı olarak düzgün kesilmiş andezit bloklar kullanılmıştır. Atkılı bir şekilde yerleştirilmiş bloklarda anathyrosis uygulandığı görülmektedir. Öte yandan, bazı taş sıralarının kaba, bazılarının ise düzgün bir şekilde işlenmiş olması, yüzey düzeltmelerini henüz tamamlanmamış olduğu izlenimini uyandırmaktadır. Yapının inşa tekniklerine dair izler, örneğin taşları yerine yerleştirmede kullanılan küskü delikleri veya kenet yuvaları gibi özellikler yer yer görülmektedir. Bir kurşun kenet in situ durumda saptanmıştır (Resim 2). Bunların yanı sıra, yapının çekirdeğini oluşturan temel kısmının yumruk büyüklüğündeki taşlarla doldurulmuş olduğu gözlemlenmiştir.

Bu yapının kuzeyinde, daha önce Hellenistik olduğu varsayılan şimdilerde ise Orta Çağ’ın başlarına ait olması muhtemel görünen yol ile yapı arasında irili ufaklı taşlardan oluşan bir dolgu saptanmıştır (Bakır 2011, s. 92-93). Yapının güney kesiminde gerçekleştirilen sondaj çalışmalarında da, aynı niteliğe sahip bir dolgu ile karşılaşılmıştır (Resim 3).

Yapının ortaya çıkarılması sırasında ele geçen seramik buluntuları karışık niteliktedir. Ele geçen malzemeler arasında en geç tarihli örnekler, MÖ 4. yüzyıl daldırma firnisli kâselerdir. "Yapı dolgusu" veya "çekirdek" olarak tanımlanabilecek alandan yoğun olarak siyah firnisli Attika ve Attika taklidi seramikler (MÖ 5. - 4. yy) ele geçmiştir. 
Kare planlı yapının kazı çalışmaları sırasında, yapının doğusunda işlevi tam olarak anlaşılamamış, kuzey-güney doğrultulu yerleştirilmiş andezit bloklardan oluşan bir başka taş sırası daha, adeta döşeme gibi düzenlenmiş bir şekilde bulunmuştur. 12,07 m uzunluğa sahip olan taşlarla döşeli bu alan kuzeyde 1,51 m, güneyde 1,33 m enindedir. Blok taşların araları boyutları değişken şekilsiz taşlarla doldurulmuştur (Resim 4). Bu döşeme ve taşların arasında bulunan malzemeler geniş bir skalaya sahiptir. Korint malları, siyah firnisli, gri monokrom ve yerel üretim malzemeler arasında, tarihlenebilir en erken malzeme, tarafimızdan Lydos'a (MÖ.560-540) atfedilen ${ }^{1}$ bir amphora gövde parçası (Resim 5) ile MÖ 4. yüzyılın ilk çeyreğine tarihlenen dışa çekik ağızlı kase² formlarıdır (Resim 6).

Yapının doğusunda kuzey-güney yönde yerleştirilmiş andezit blokların altında farklı evrelere ait yapılanmanın olup olmadığını ortaya çıkarmak amacıyla, yapının kuzey kesiminde 2,50 x 1,95 m ölçülerinde bir sondaj açılmıştır (Resim 7). İlk olarak açığa çıkarılan andezit bloğun altında toplamda 10 adet taş sırası daha açığa çıkarılmıştır. İlk altı sıra taşın birbiriyle orantılı bir şekilde yerleştirildiği görülmüştür. İlk üç sıra taş aşırtmalı bir şekilde, basamaklar oluşturarak yerleştirilirken, sonraki üç sıra taş birbirinin üstüne yerleştirilmiştir. Daha sonra gelen dört sıra taş yine merdiven basamağını andırır şekildedir; fakat diğer taşlardan farkı kyklopik yapıda ve özensiz olmalarıdır. Bu sondajda bir sonraki yıl yapılan kazı çalışmalarında benzer özelliklerde iki taş sırası daha açığa çıkarılmıştır. Açığa çıkarılan en alt iki taş sırası bir yelpaze misali üstteki sıralara verev olarak çıkıntılı yerleştirilmiştir. Blok taşların çoğu andezitten, birkaç tanesi ise kireç taşından yontularak kabaca dikdörtgen prizma şekli verilmiştir. Yükseklikleri genel olarak uyumlu olmakla beraber en ölçüleri çeşitlidir.

Kare planlı yapının doğusundaki bu sondajda çoğunluğu andezitten olmak üzere toplamda 12 taş sırası açığa çıkarılmıştır. Ortaya çıkarılan andezit blok sıralarının toplam yüksekliği 7,20 m.' dir. Yapı ile birlikte toplam yükseliği ise 9 m’ye ulaşan bir mimari öğe olduğu anlaşılmaktadır. Ele geçen malzemeler arasında MÖ 6. yüzyılın ikinci çeyreğine tarihlenen İonia kyliksi ${ }^{3}$ (Resim 8a), MÖ 7. yüzyılın ilk yarısı Protokorint Döneme tarihli bir adet skyphos (Resim $8 b)^{4}$ ve gri monokrom seramik parçaları ele geçmiştir.

Sondaj kazısında açığa çıkarılan basamaklı taş sıralarının, glacis adı verilen bir istinat duvarına ait oldukları anlaşılmıştır. Höyüklerde destek amaçlı basamaklı istinat duvarlarının kullanımı yaygındır. Anadolu'da benzer bir biçimde bir destek duvarı Gordion’da karşımıza çıkmaktadır.

Örn. Bkz. Boulter ve Luckner 1976, 1, 19, lev. (806) 26.3; Calderone 1985, 7, lev. (2685, 2686) 1.1-2, 2.1-4. Sparkes ve Tallcott 1970, 292, fig. 8.803.

Walter-Karydi 1973, lev. 44, 382.

Payne 1962, lev. 27. 558-567. 
Glacise ait taş sıraları açığa çıkarılırken ele geçen malzemeler arasında en geç tarihli seramikler, MÖ 6. yüzyıl ortalarına aittir ve bu yapı için post antequem tarih belirtmektedir. Bu nedenle glacisnin ilk evresinin, Lydia Dönemi’nde inşa edilmiş olduğunu düşünmek yanlış olmayacaktır (Resim 9a-c) $)^{5}$.

Kare planlı yapının sondaj açılmayan doğu kesiminde seviye inme çalışmalarında kuzeygüney doğrultulu yumruk büyüklüğünde kireç taşlarından oluşan bir başka döşeme ile karşılaşılmıştır (Resim 10). 5,65 m uzunluğunda, 1,60 m genişliğinde olan bu döşeme yer yer tahrip olduğu için sınırları izlenememiştir. Döşeme üzerinde az miktarda bezemesiz, ne yazık ki, herhangi bir tarih vermeyen turuncu hamurlu ve gri monokrom gövde parçaları ele geçmiştir. Bu döşemenin yapı inşa edildikten çok sonra, belki de Orta Çăğ da yapıldığı düşünülebilir.

Öte yandan döşemenin batısında, döşemeyle aynı seviyede uzunluğu $6,10 \mathrm{~m}$, genişliği ise 65-15 cm arasında değişkenlik gösteren yoğun miktarda karbonlu bir alan gözlemlenmiştir (Resim 10). Höyüğün etrafında yapılan jeolojik araştırmalar sonucunda Daskyleion'un İlk Çağ'da karaya çok küçük bir toprak parçasıyla bağlanan ve anakarayla arasında bir haliç bulunan bir yarımada olduğu ortaya çıkarılmıştır ${ }^{6}$. Bu saptama doğrultusunda gölün kare planlı yapının eteğine kadar dayanıyor olması gerekmektedir. Bu varsayımdan yola çıkarak bu karbonlu alanın iki uçta incelerek sivri birer uç oluşturan bir şekle sahip olduğu da düşünülerek göl içinde ulaşımı sağlayan ve buraya bağlanmış ahşap bir kayığa ait olup olmadığı sorgulanabilir. Buna karşın aşağı yukarı aynı seviyede ortaya çıkan kireç taşı döşeme bu varsayıma uymamaktadır. Nitekim karbonlu alan döşemeyi kesiyor gibi görünmektedir. Karbonlu alanın üzerindeki toprak örtüsünden ele geçen malzemeler MÖ 5. ve 4. yüzyıl ağırlıklıdır. Dolayısıyla döşeme ve karbonlu alanın MÖ 4. yüzyıldan daha erken bir tarihe ait olduğu tahmin edilmektedir.

\section{Tartışma ve Sonuç}

Daskyleion'un doğu yamacında, yerleşmeye giriş niteliğindeki ve Hellenistik Dönem'e tarihlenen yolun güney kısmında kalan kare planlı yapının korunagelen yüksekliği 2,30 m'dir. Üzerine oturduğu andezit ve kireçtaşı kabaca dikdörtgen prizması şeklinde biçimlendirilmiş (köşeleri yuvarlatılmış) blok taşlardan örülmüş, derinleştikçe taş sıralarının basamak gibi öne doğru çıktığı duvar örgüsünün korunagelen yüksekliği ise 7,20 m'dir ve toplamda on iki basamaktan/taş sırasından oluşur (Resim 11).

Kare planlı yapı ve üzerine oturduğu basamaklı yapı toplamda dört mimari evreye sahiptir (Resim 12). Buna göre ilk evre, yapının kuzey kesiminde açılmış sondajın en alt seviyesinde ortaya çıkan ve destek duvarı glacisin dış yüzünü oluşturan duvarın aksından

5 Resim 11a için bkz İren 2010, 262 Resim 8; Resim 11b için bkz. İren 2003, lev. 54. 261-262.

6 Prof. Dr. Kaan İren yürütücülüğünde tamamlanan 109K363 numaralı TUBİTAK projesi. 
daha farklı bir aksa sahip bir duvar ile doğuya doğru ona dik açı yaparak organik olarak birleşen bir duvardan oluşan bir yapı evresidir. Bu yapı evresinin duvarları destek duvarına göre daha düzensiz taşlardan örülmüştür. Bu ilk yapı evresi, yapının kuzeyinden akan, beyaz kil içeren, taşlı ve kumlu bir toprakla dolarak sonlanmıştır. Akan toprağın killi ve kumlu yapısından dolayı suyla taşınmış olduğunu ileri sürmek mümkündür. Sondajın en alt tabakalarında, bu seviyelerde çok az malzeme ele geçmiş olması da doğal yollarla dolmuş olduğuna dair düşüncemizi güçlendirmektedir. Ardından ikinci yapı evresi olarak eğimli/ basamaklı yapıya sahip destek duvarı, ilk yapı evresindeki duvarların üzerine oturacak şekilde ama farklı bir aksta inşa edilmiştir. İlk iki evre kazılar sırasında bu seviyelerden ele geçen en erken ve en geç tarihlenebilir seramik malzemeden yola çıkılarak MÖ 700550/525 yılları arasına tarihlenmiştir. Üçüncü yapı evresinde destek duvarının önünde/ doğusundaki alan toprakla doldurulmuş, başka bir deyişle destek duvarı tanzim edilmiş ve üzerine kare planlı yapı inşa edilmiştir. Söz konusu alanda ele geçen en geç malzemenin MÖ 4. yüzyıla tarihleniyor olmasından yola çıkarak alanın bu dönemde doldurulduğu sonucuna varılmıştır. Dördüncü bir yapı evresindeyse kare planlı yapının doğusunda, yapının doğu duvarına paralel bir şekilde uzanan, dış yüzü aşağı yukarı benzer büyüklük ve şekillerde taşların dizilmesiyle oluşturmuş ve iki duvar arasındaki boşluğa doldurulmuş dolgu taşlarını sınırlayan, kaldırım benzeri bir mimari unsur inşa edilmiştir. Bunun hangi dönemde yapıldığını anlamak güçtür, ama kare planlı yapının inşasından sonraki bir dönemde yapıldığını söylemek mümkündür. Çünkü söz konusu oluşumun arkasında kare planlı yapının doğu duvarının taşları devam etmektedir.

MÖ 700-525 yıllarında inşa edilmiş olan basamaklı destek duvarı toplam on iki taş sırasına sahiptir. Bu taş sıralarının en üstteki üçü birer basamak izlenimi verecek şekilde öne doğru çıkıntı yaparak yerleşmiştir. Yükseklik olarak birbirine çok yakın, ama en olarak çeşitli ölçülere sahip andezit ve kireç taşı bloklardan inşa edilmiştir. Bu bloklar köşeleri yuvarlatılmış kaba birer dikdörtgen prizması şeklindedir. Araştırma sonucunda bu yapıya çok benzeyen bir yapının Gordion'da yer aldığı saptanmıştır (Resim 13). Sitadelin girişine yakın konumdaki istinat duvarı, sitadelle birlikte Gordion'daki büyük tahribatın ardından MÖ 8. yüzyılda gerçekleştirilen imar faaliyetleri kapsamında inşa edilmiştir. İstinat duvarının molozdan bir çekirdeği ve çok renkli, kesme taşlardan inşa edilmiş bilindiği kadarıyla $20 \mathrm{~m}$ yüksekliğinde basamaklı bir destek duvarı vardır (Burke, 2012, s. 205,211). Bu yapı eğimli yüzeyi, kullanılan taşların malzemesi, renkliliği ve biçimi açısından Daskyleion'daki duvar ile büyük benzerlik göstermektedir.

Kare planlı yapıda taşların bir arada tutulmasında kurşun kenetler kullanılmıştır. $\mathrm{Bu}$ yapının duvar örgüsüne en çok benzeyen örneklerden biri Antandros Kenti'nde yer almaktadır (Resim 14). MÖ 4. yüzyıla ait 3.26 m kalınlığa sahip sur duvarı, yer yer on sırası üst üste korunmuş (3.00-3.25 m yükseklikte), dış yüzleri bosajlı dikdörtgen bloklardan 
oluşturmaktadır. Bazı bölümlerde blokların yatay kullanılmasıyla güçlendirilen duvarın iç dolgusu moloz taşlardan oluşur (Polat, Polat, Yağız, Zunal, \& Yıldırım, 2009, s. 43-45).

Kare planlı yapı yer yer yüzeyi düzeltilmiş yer yer ise anathyrosisli aynı yükseklikte ama farklı enlerde kireç taşı bloklardan inşa edilmiştir. Yapının içi çok yoğun taşı bir dolguyla doldurulmuştur. Bu nedenle bu yapının bir kuleden ziyade bir mezarın podyumu olabileceği düşünülmektedir. Bu yapı, Anadolu'da en yakın örneklerini gördüğümüz Ksanthos Nereidler Anıt1 $^{7}$, Halikarnassos Maussolleion' ${ }^{8}$, Ephesos Belevi Anıt1 ${ }^{9}$ mezarlarındaki podyumu andirmaktadir.

Sonuç olarak bu çalışmada, kare planlı yapı ve çevresinde en az dört evreli bir inşa faaliyeti olduğu saptanmıştır. İlk evreyi oluşturan Lydia Dönemi'nde, kentin girişine Anadolu'da da benzer örneklerine rastlanan glacis adı verilen basamaklı ve eğimli bir istinat duvarı yapılmıştır. Bundan sonra bu alandaki en önemli değişiklik, MÖ 4. yüzyıla tarihlendirilen kare planlı yapının inşa edildiği dönemdir. Bu yapının işlevi şimdiye kadar kesin olarak bilinmemekle birlikte, inşa edildiği konum ve büyüklüğü itibariyle kentin MÖ 4. yüzyıla ait önemli yapıları arasında sayılabilir.

Finansal Destek: Bu çalışma T.C. Kültür ve Turizm Bakanlığı, Türk Tarih Kurumu, Balıkesir Büyükşehir Belediyesi, İstanbul Üniversitesi Bilimsel Araştırma Projeleri Koordinasyon Birimi SBA 2016-21847 numaralı proje ve Muğla Sıtkı Koçman Üniversitesi Bilimsel Araştırma Projeleri Koordinasyon Birimi 15/142, 17/261, 17/206, 17/095, 17/128 ve 15/202 numaral1 projeleri ile desteklenmiştir. Çalışmayı destekleyen tüm kurumlara teşekkür ederiz. 


\section{Kaynakça}

Bakır, T. (2011). Daskyleion: Balıkesir'in eski çağlardaki valilik merkezi. Balıkesir: Balıkesir Valiliği.

Burke, B. (2012). The Rebuilt Citadel at Gordion: Building A and the Mosaic Building Complex. In C. B. Rose, (Ed.), The Archaeology of Phrygian Gordion, Royal City of Midas (pp. 202-218). Philadelphia, University of Pennsylvania Museum of Archaeology and Anthropology Press.

Boulter, C. \& Luckner K. T. (1976). Corpus vasorum antiquorum. Toledo. The Toledo Museum of Art.

Calderone, A. (1985). Corpus Vasorum Antiquorum. Italia, 61. Agrigento, Museo Archeologico Nazionale, 1. Rome: Agrigento, Museo Archeologico Nazionale 1, L’Erma di Bretschneider.,

Demargne, P. (1990). Das Nereiden-Monument von Xanthos. Götter Heroen

Herrscher in Lykien (pp. 65-69), Wien: Anton Schroll.

İren, K. (2010). A New Discovery in Dascyleum: the Persian Destruction Layer. P. Matthiae, F. Pinnock, L. Nigro, N. Marchetti \& L. Romano (Eds) Proceedings of the 6th International Congress on the Archaeology of the Ancient Near East 5 May - 10 May 2008, "Sapienza", Università di Roma (pp. 249263), Wiesbaden: Harrassowitz.

İren, K. (2003). Aiolische Orientalisierende Keramik. İstanbul: Ege Yayınları.

Jeppesen, K. (2002). The Superstructure. A comparative analysis of the architectural, sculptural, and literary evidence. Aarhus: Aarhus University Press.

Payne, H. \& Dunbabin, T. J. (1962). Perachora. The Sanctuaries of Hera Akraia and Limenia II. Oxford: Clarendon Press.

Polat, G., Polat, Y., Yağız, K., Zunal, O. \& Yıldırım, B. (2009). Antandros 2007 Yılı Kazıları. Kazı Sonuçları Toplantısı 30 (4), 39-60.

Praschniker, C. \& Theuer, M. (1979). Forschungen in Ephesos, Band VI, Das Mausoleum von Belevi. Viyana: Österreichisches Archaeologisches Institut.

Sparkes, B.A. \& Tallcott, L. (1970). Agora XII: Black and Plain Pottery of the 6th, 5th and 4th Centuries B.C. Princeton, N.J. : American School of Classical Studies at Athens.

Walter-Karydi, E. (1973). Samos VI, 1. Samische Gefasse des 6. Jahhunderts v. Chr. Landschaftsstile ostgriechischer Gefasse. Bonn: R. Habelt. 


\section{RESIMLER}

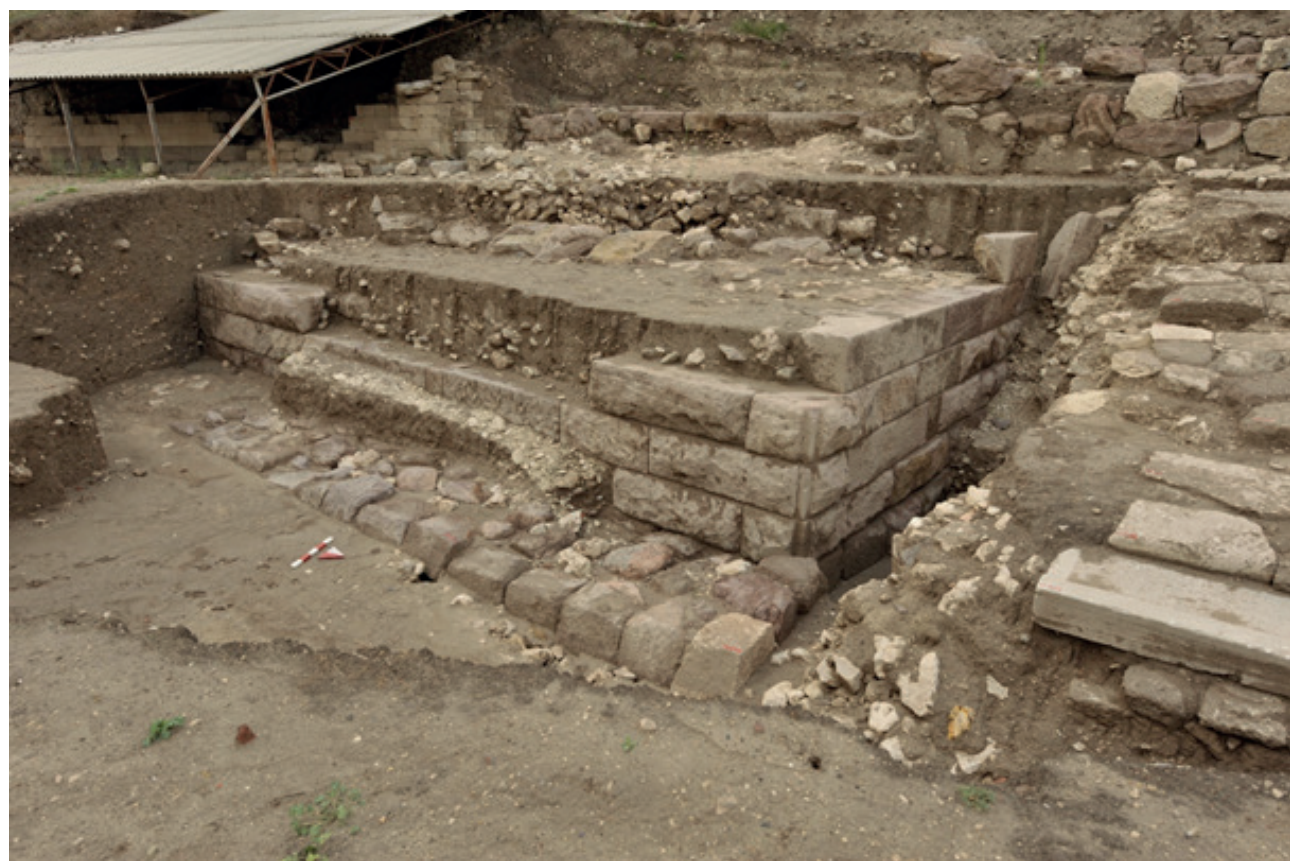

Resim 1. Projenin başında Kare Planlı Yapı'nın durumu.

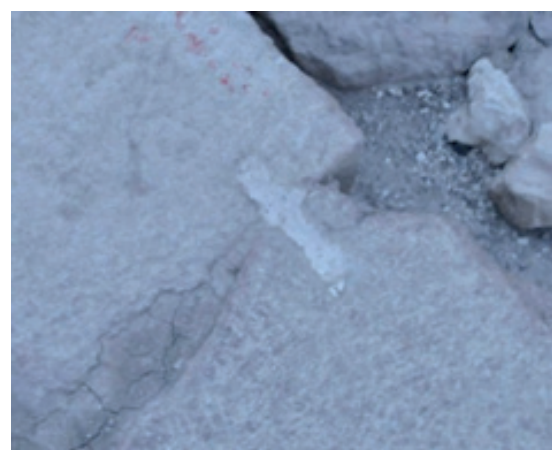

Resim 2. Bloklardan birinin üzerinde korunagelmiş kenet. 


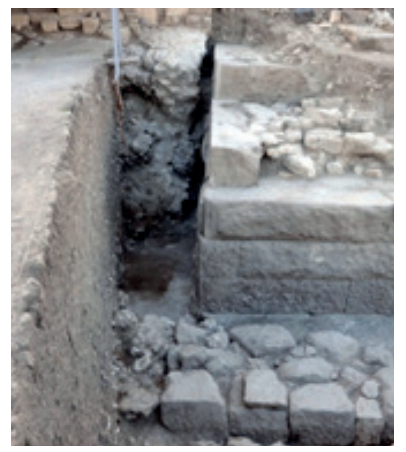

Resim 3. Yapının güney yüzü ve dolgu.

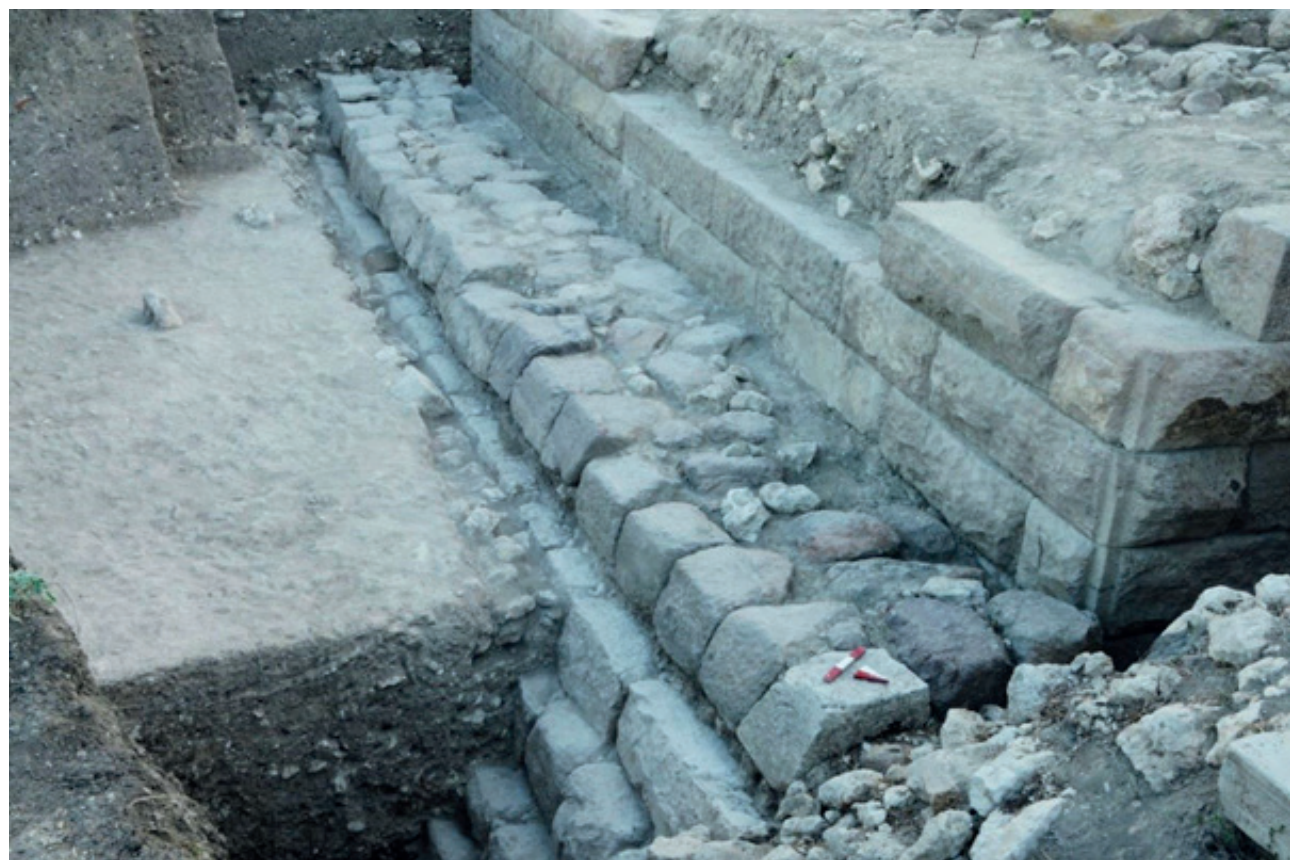

Resim 4. Yapının doğu kenarı boyunca uzanan andezit taş örgüsü. 


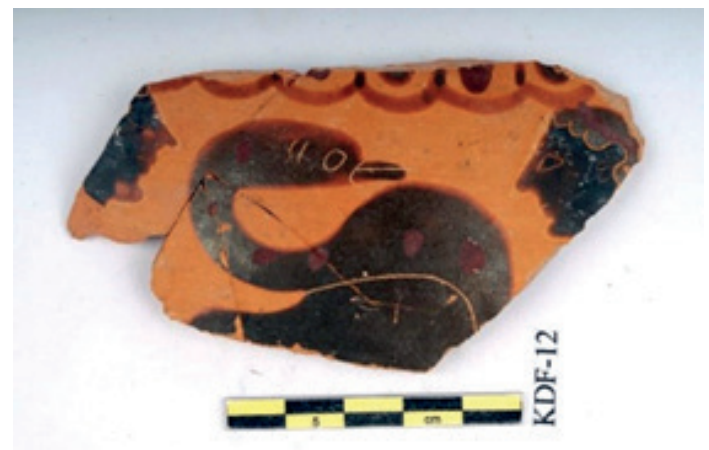

Resim 5. Klazomenai amphora parçası (MÖ 6. yy’ın üçüncü çeyreği).

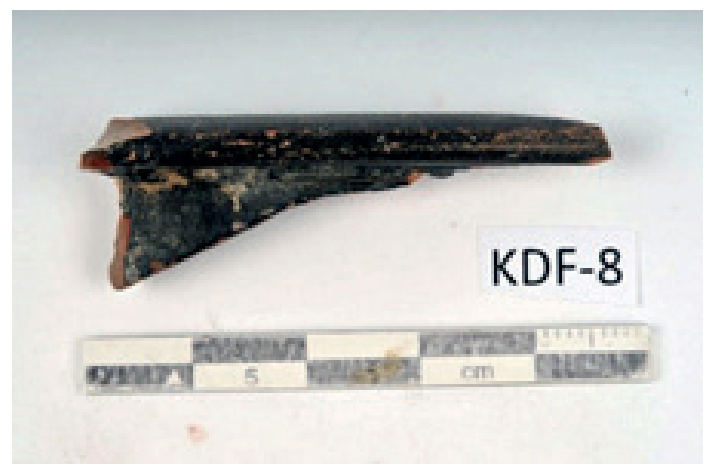

Resim 6. MÖ 4. yy’a tarihlenen dişa çekik ağızlı kase parçası. 


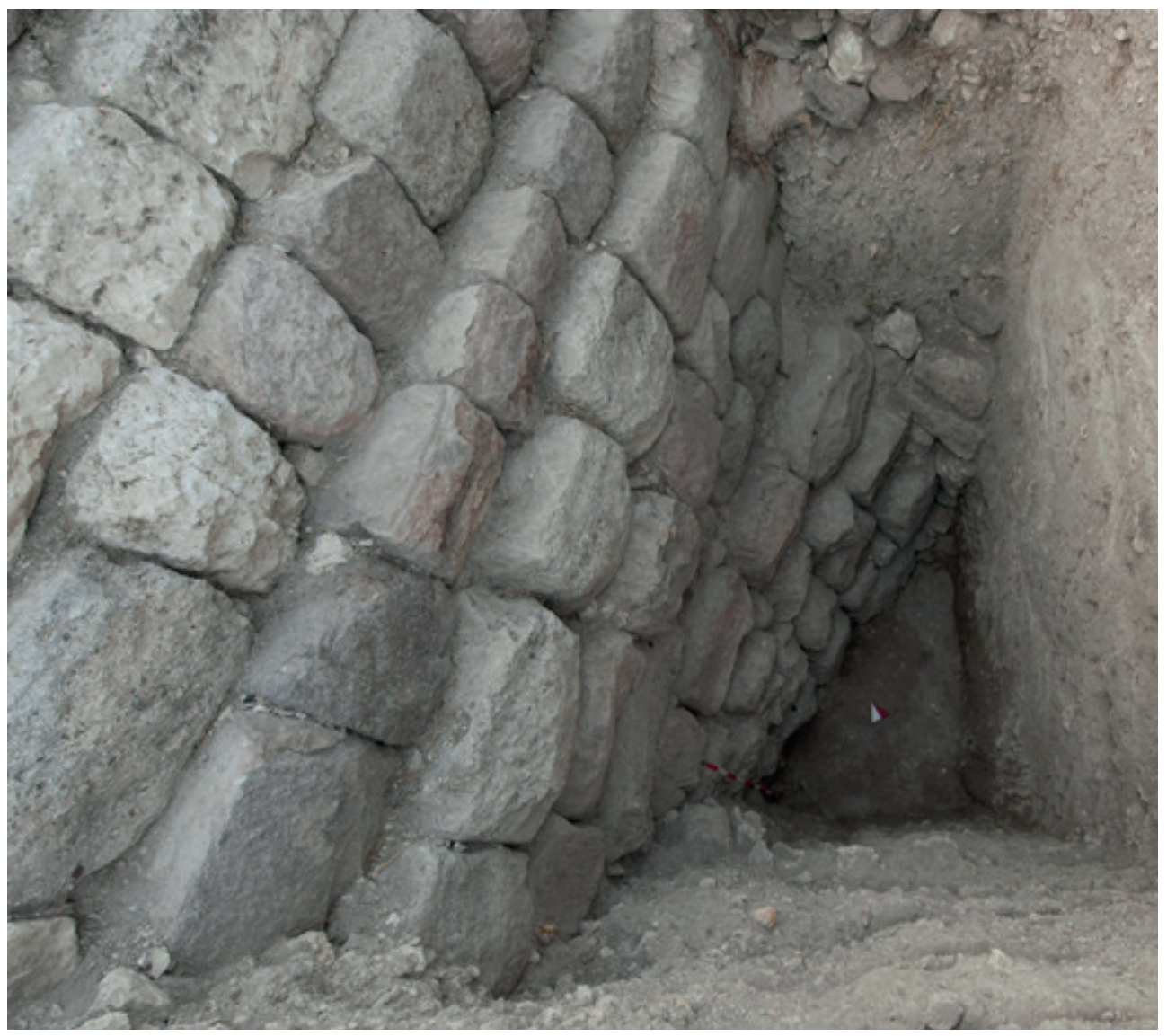

Resim 7. Yapının doğu kenarı boyunca uzanan andezit taş örgüsü.

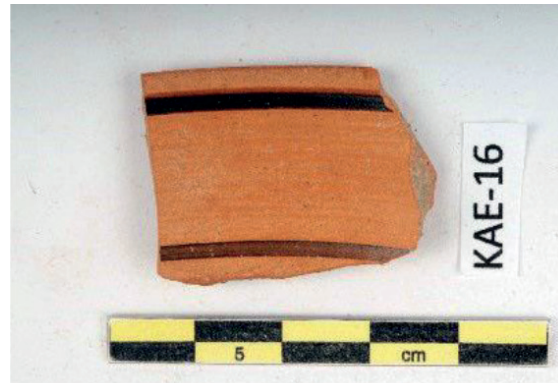

$\mathbf{a}$

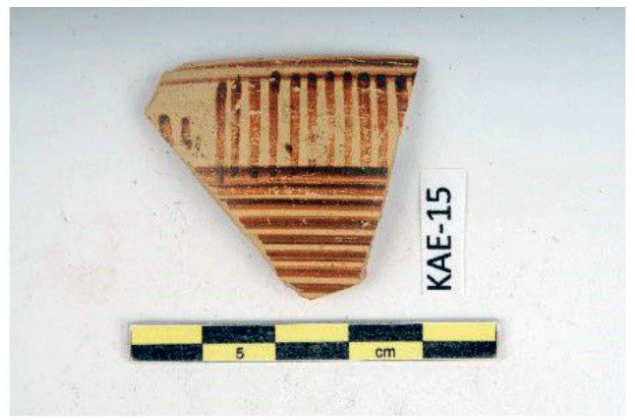

b

Resim 8a-b. Sondajda ele geçen seramikler. 


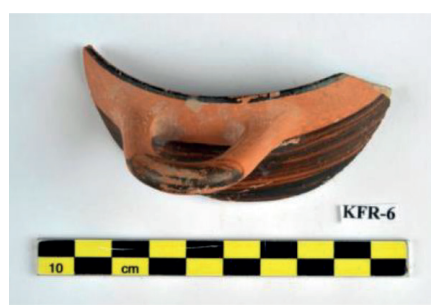

a

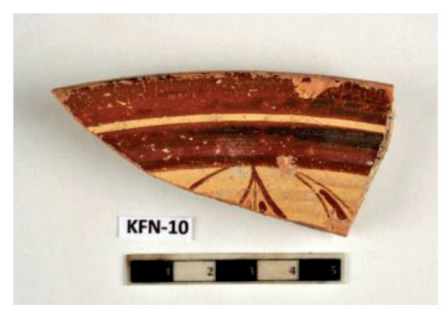

b

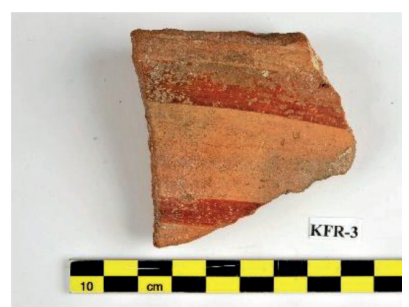

c

Resim 9a-c. Sondajda ele geçen Lydia Dönemi seramikleri (MÖ 6. yy ortaları).

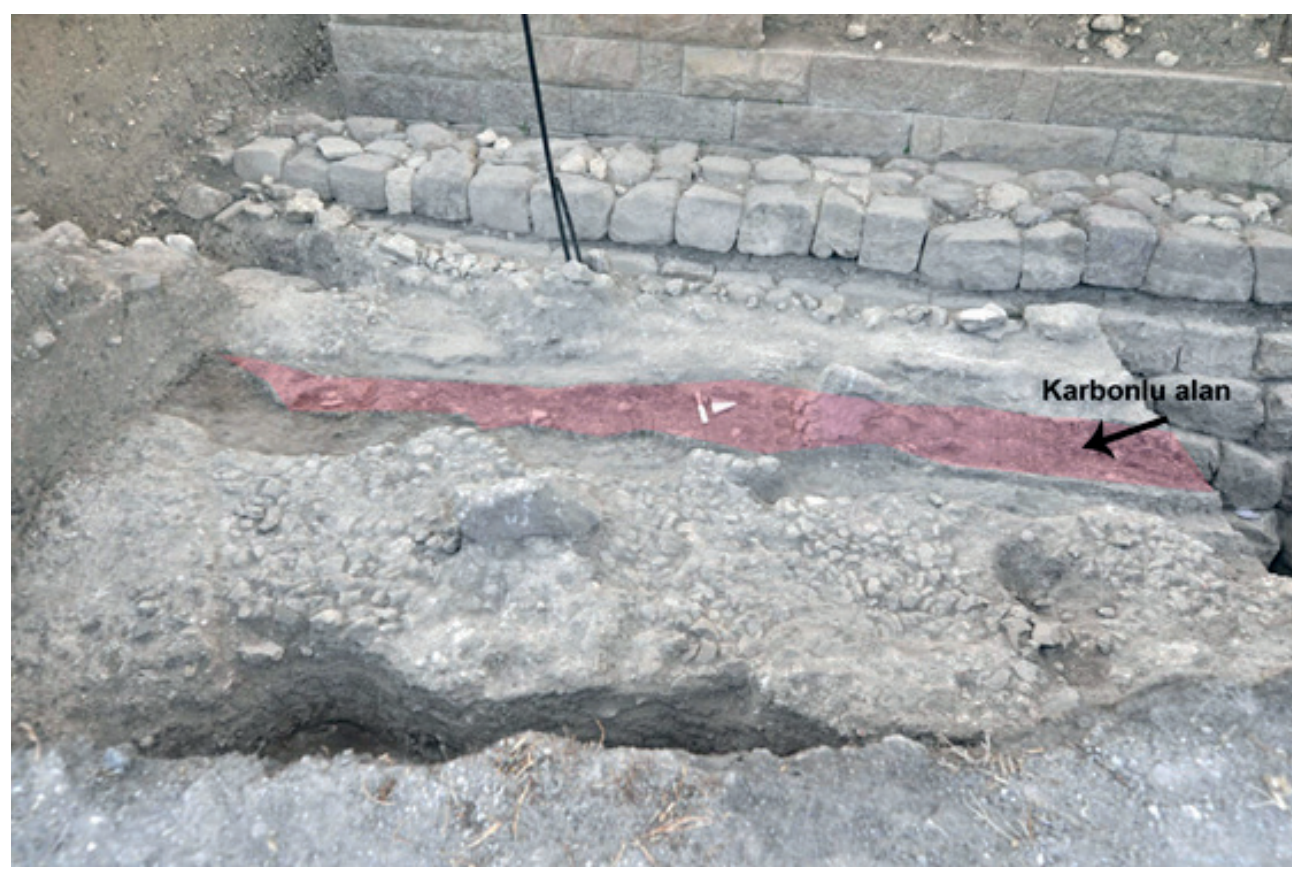

Resim 10. Kare Planlı Yapı'nın doğusunda ortaya çıkan kireç taşı döşeme ve karbonlu alan. 


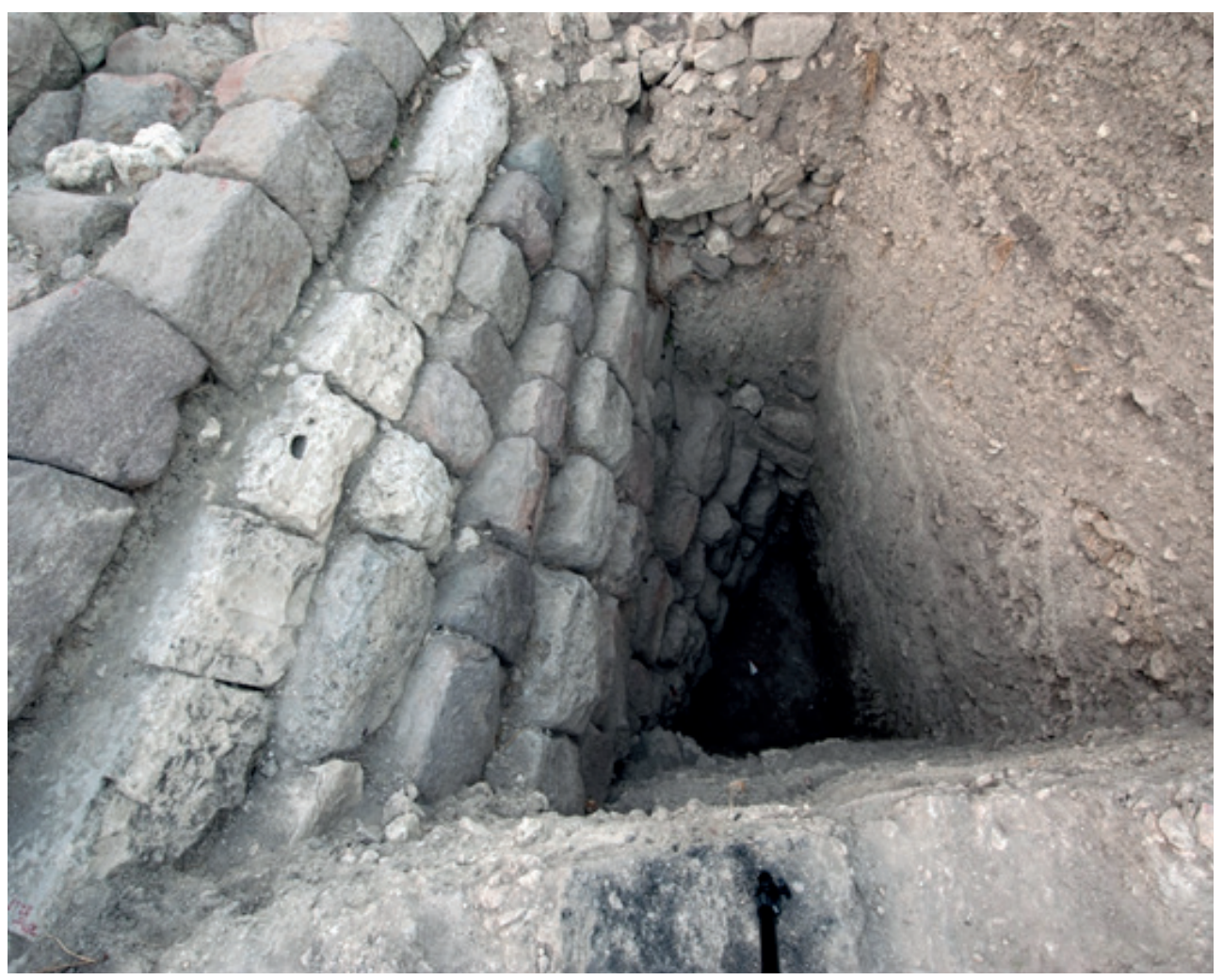

Resim 11. Sondajda görülen duvar örgüsü. 


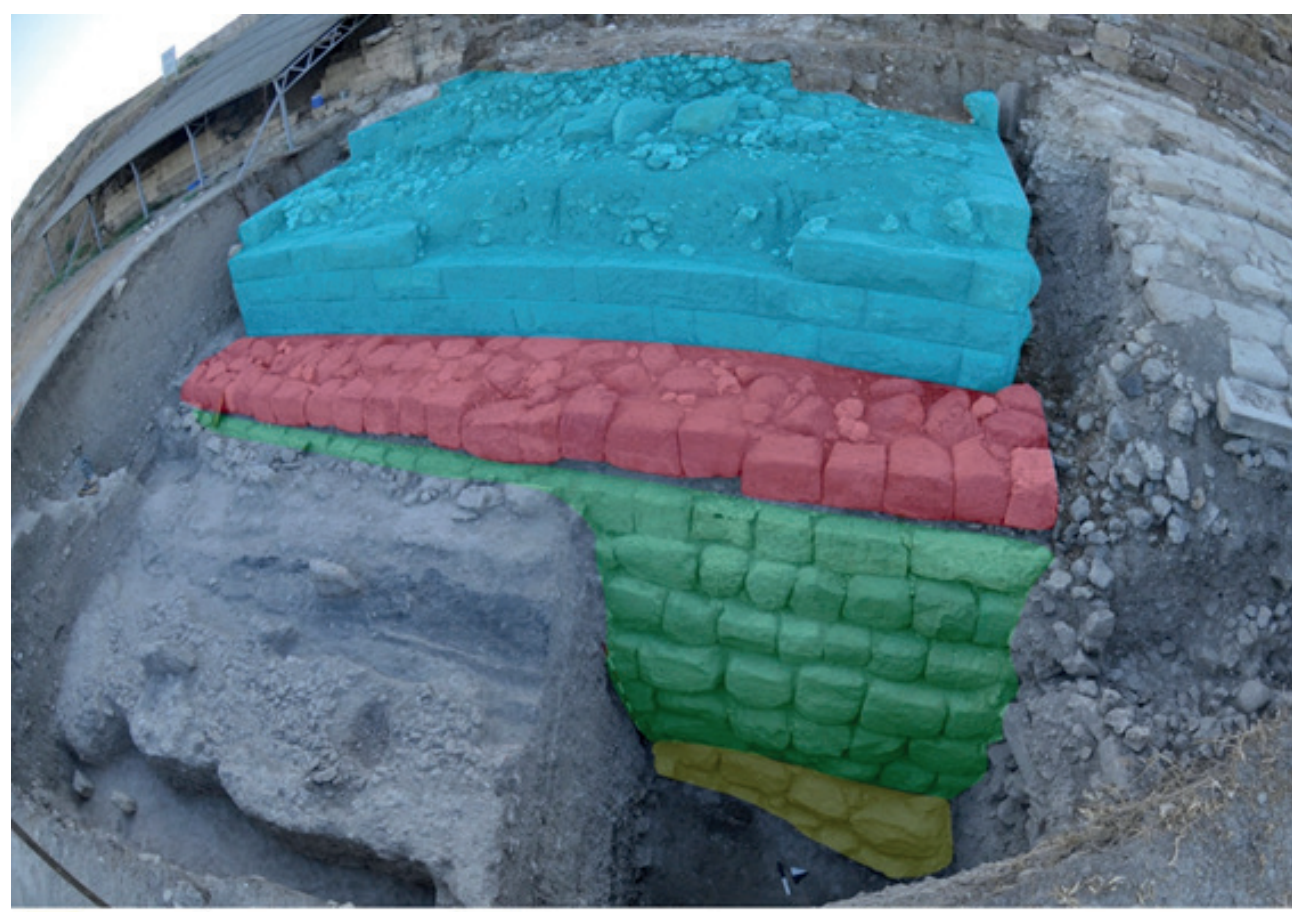

1. evre (MÖ 700-550/525)

2. evre (MO 700-550/525)

Oçüncū evre (MÖ 4. yüzyıl)

Dördüncü evre

Resim 12. Kare Planlı Yap1, destek duvarı ve en alttaki erken yapının evreleri. 


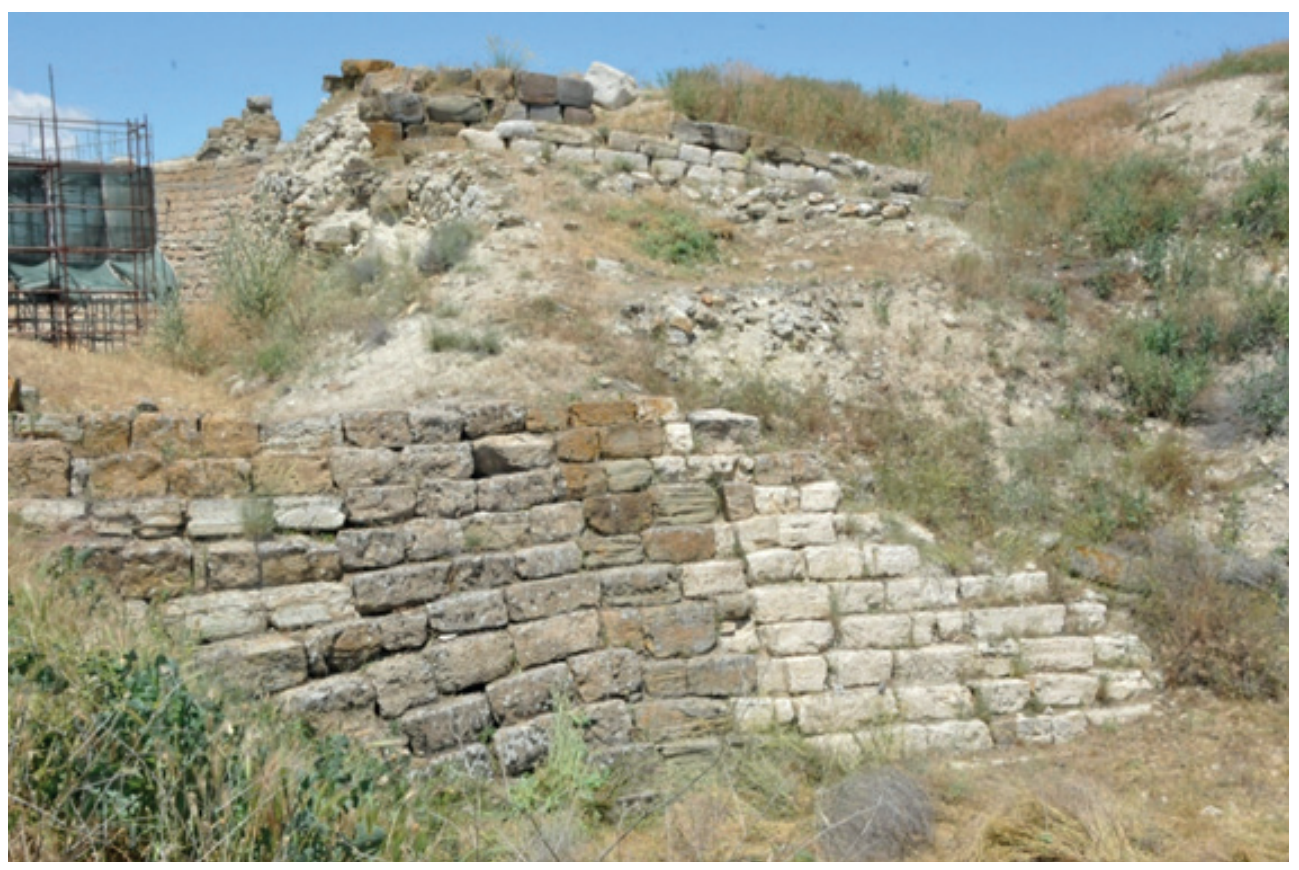

Resim 13. Gordion' daki destek duvar1. 


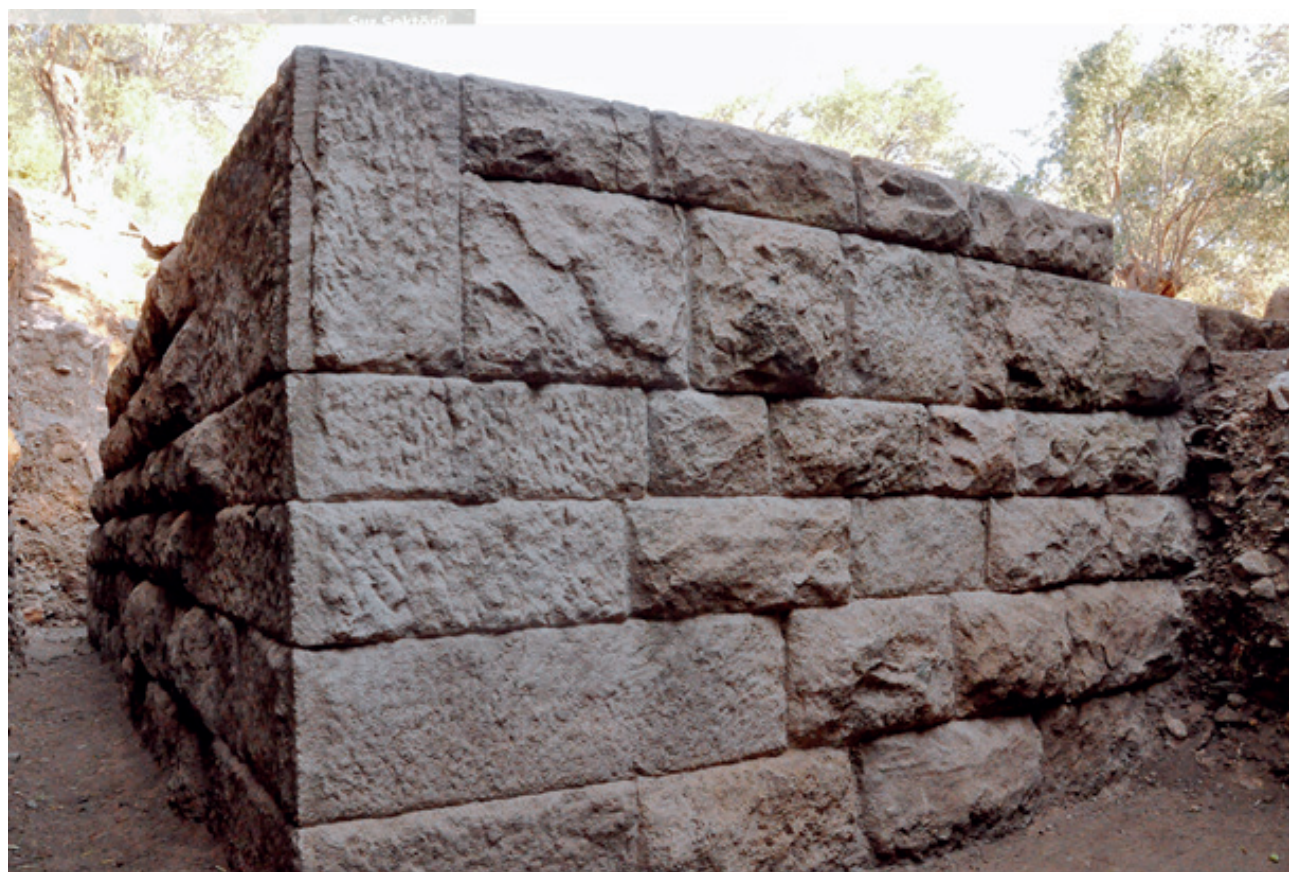

Resim 14. Antandros'daki MÖ 4. yüzyıl kent suru. 